and it becomes, on division of numerator and denominator by $\mathbf{D}_{x}$,

$$
\mathrm{P}=\frac{1}{1-\frac{(1+r)^{\frac{1}{\mathrm{M}} \mathrm{M}_{x \mid n}}}{\mathrm{D}_{x}}} \cdot \frac{\mathrm{N}_{x+\mathrm{n}}}{\mathrm{D}_{x}} ;
$$

or, writing $Q$ for $\frac{(1+r)^{d} M_{x \mid n}}{D_{x}}$, which is the value of a return of $f 1$,

$$
P=\frac{1}{1-Q} \cdot \frac{N_{x+n}}{D_{x}}
$$

This is Mr. Younger's expression, which, being thus identical with mine, ought, if properly applied-if the proper values of the elements composing it be made use of-to give the same numerical result. Mr. Younger, by an analytical process, which $I$ think I am warranted in calling unnecessarily refined, determines an expression for $Q$ which enables him to assign $\cdot 42556$ as its value in the case in hand, which value differs but little from that given by my table-namely, -425534 . It is in the remaining element of the expression then-the annuity valne-that the principal source of the discrepancy must be sought. Accordingly we find that $\mathrm{Mr}$. Younger here uses the ordinary deferred annuity value; and in so doing-ignoring one of the contingencies on which, during the first 10 years, the valne of the annuity depends-he, singnlar to say, commits an error precisely similar in character to that which he points out as vitiating $\mathrm{Mr}$. Stephenson's investigation. The effect is, that the ralne thrs assigned to $P$ is one that will provide an annuity not only for those who neither die nor withdraw during the 10 years, but also for such of the latter class as shall survive the term!

Using the annnity value derived from my table, and Mr. Younger's value of $\mathrm{Q}$ (in which there is probably some arithmetical error), his formula gives for $\mathrm{P}, 5.60944$." Using also ny value of $Q$, it gives, of course, $5 \cdot 60920$.

I must apologise for having occupied so mnch space. I hope, however, it may be found that something has been done towards the elucidation of the various points of interest that have arisen.

$$
\text { I am, Sir, }
$$

Yours most obediently,

London, 11 th May, 1866.

P. GRAY.

\title{
ON MR. YOUNGER'S LETTER, AND ON THE GENERAL SOLUTION OF PROBLEMS INVOLVING DISTINCT CONTINGENCIES.
}

\section{To the Editor.}

SrR,-After the non-success of my endeavour to convince Mr. Stephenson of the failure of his attempt to solve a new problem in life contingencies, I declared my intention of retiring from the contest; as I felt satisfied that a continnance of the discussion with an opponent who (in the face of the evidence I had adduced) still adhered to his notion that he had succeeded in determining the value of the "option of withdrawal," was not likely to lead to any useful resnlt. The snbject, however, having been taken ap by Mr. Younger, in an able letter published in your last Number, wherein that gentleman (after endeavouring to point out the source of Mr. Stephenson's

* See Mr. Younger's letter, p. 118, - ED. J. I. A.

vOL. XIII, 
singular error) proceeds to rednce the problem within the bounds of possibility - so far at least as regards its theoretical solution-by assuming the existence of a definite law of withdrawal, I now venture to request the favour of some further space for the discussion of the subject on its new footing.

Whatever opinion may be entertained of the practical value of the inquiry (on which point, before concluding, I shall have a few words to say), there can be no question that the investigation of the problem, on the basis upon which Mr. $Y$. has placed it, is a perfectly legitimate subject for the pages of the Journal, even if it be regarded merely in the light of a mathematical exercise. I propose, therefore, in the first place, to show wherein Mr. Younger has erred in the solntion which he has given; and in the second, to point out what appears to me the true mode of dealing generally with problems of this and of a cognate character.

That Mr. Yonnger's solution is erroneous is apparent from the result of his numerical example. For he finds that, npon the hypothesis of each year's withdrawals being one-twentieth of the number existing at the beginning of the year, the premium for an annuity on a life aged 50 , deferred 10 years, receives an addition, consequent upon the introduction of the option of withdrawal, of no less than 50 per cent.! Now I am prepared to maintain, that, in consequence of the "value" of a policy of this description being (as I had occasion to point out in a former letter) always in excess of the amount of the preminm paid, it must inevitably follow that the limitation of the sum to be received on withdrawal to the amonnt of the preminm only, must, as a matter of calcnlation, have the effect of reducing the premium instead of raising it. And examining Mr. Younger's equation of condition, Q.P $x+\frac{N_{x+n}}{D_{x}}=P_{x}$, where $Q$ denotes the value of $f 1$ to be paid at death or withdrawal, we may see at once that it contains a very material error, inasmuch as it assumes that the value of the annuity is affected by the risk of death only, in the period during which it is deferred. The equation, in fact, expresses the condition necessary for determining the value of a deferred annuity with the return of the preminm in the event of death, and also with the option of receiving a gratuity of $\mathbf{P}_{x}$ (unconditionally) any time before the annuity commences-assuming, of course, that the number who in each year will avail themselves of this option will be limited in accordance with the supposed "law of withdrawal."

But independently of the oversight here adverted $t o$, I find fanlt with Mr. Younger's solution as being by no means the simplest which the problem admits of. For if we consider the actual effect of the introdnction of the contingency of withdrawal, we shall see, first, that its operation is confined to the period intervening between the date of the contract and the commencement of the amuity; and, secondly, that daring the period in question its effect is identical with that of the risk of death. We have, therefore, in dealing with the problem, merely to form a table of the numbers remaining from year to year in a body or community subject to the combined action of death and withdrawal from age $x$ (supposed to be the age at entry) to age $x+n$, at which the annuity is to be entered upon; and then to continue it from the latter age npon the supposition that the members then remaining are affected by the risk of death only. The usnal $D$ and $\mathrm{N}$ colomns being formed from a table so constructed, the ordinary 
formula for a deferred annuity with the return of the preminm at death, viz., $\frac{\mathrm{N}_{x+n}}{\left(\mathrm{~N}_{x-1}-\mathrm{N}_{x+n-1}\right)(1-v)+\mathrm{D}_{x+n}}$, shonld give the value of the proposed benefit.

Seeing, then, that the whole diffculty of the problem lies in the construction of a table of the values of $\lambda_{x}$, or the numbers remaining, at each successive year of age, among a body of members subject to death and withdrawal, I shall confine myself (so far as regards this part of my subject) to the consideration of the best means of effecting this object. And first I observe that, in the numerical solution of his problem, Mr. Younger assumes that the number withdrawing in each year bears a constant proportion to the number entering upon the year-an assumption which involves the supposition that the inclination or disposition to withdraw increases with the risk of death, for otherwise the proportion of yearly withdrawals would become less as the average quantity of existence enjoyed during each year diminishes. I shall, on the other hand, assume the law of withdrawal to be entirely independent of the law of mortality-a supposition which, besides being somewhat more consistent with reason, will, I think, be still more fully justified by the simplicity of the results to which it will lead us.

With the view of generalizing the investigation, and of adapting it to the assumption last mentioned, let us (in the first instance) discard the ideas of death and withdrawal, and suppose merely that the body or community nnder observation, is subject to two independent contingencies, neither of which can occur more than once to the same individual, bat the happening of either of which will in no way affect the occurrence of the other. Let $p$ denote the probability that, in reference to any particular individual, a year will elapse without the occurrence of the first contingency (which we will designate by $\varepsilon_{1}$ ), and $p^{\prime}$ the same probability as regards $c_{2}$, the second contingeney. We shall then have the following five possible cases:-

\begin{tabular}{|c|c|c|}
\hline Case. & Event. & The probability of which is \\
\hline $\begin{array}{l}1 \\
2 \\
3 \\
4 \\
5\end{array}$ & $\begin{array}{l}\text { That neither } c_{1} \text { nor } \varepsilon_{2} \text { happens. } \\
\text { That } c_{1} \text { happens and } c_{2} \text { not. } \\
\text { That } c_{3} \text { happens and } c_{1} \text { not. } \\
\text { That } c_{1} \text { and } \varepsilon_{2} \text { both happen: } c_{3} \text { first. } \\
\text { " }\end{array}$ & $\begin{array}{l}p p^{\prime} \\
(1-p) p^{\prime} \\
\left(1-p^{\prime}\right) p \\
\left.\frac{1}{(}(1-p)\left(1-p^{\prime}\right)\right)^{*} \\
\frac{1}{8}(1-p)\left(1-p^{\prime}\right) \cdot{ }^{*}\end{array}$ \\
\hline
\end{tabular}

By combining these elementary cases, we obtain the following three, which are all we shall require for the purposes to which our conclusions will be applied:-

\begin{tabular}{|c|c|c|}
\hline Cases. & Event. & $\begin{array}{l}\text { The probability of } \\
\text { whieh is }\end{array}$ \\
\hline $\begin{array}{c}1 \\
2 \text { and } 4 \\
3 \text { and } 5\end{array}$ & $\begin{array}{l}\text { That neither } c_{1} \text { nor } c_{2} \text { happens. } \\
\text { 'That } c_{1} \text { happens, } c_{2} \text { not having previously occurred. } \\
\text { That } c_{2} \text { happens, } c_{1} \text { not having previously occurred. }\end{array}$ & $\begin{array}{l}p p^{\prime} \\
\frac{1}{\frac{1}{2}}(1-p)\left(1+p^{\prime}\right) \\
\frac{1}{q}\left(1-p^{\prime}\right)(1+p)\end{array}$ \\
\hline
\end{tabular}

* According to the hypothesis usnally resorted to in life contingencies, viz., that if an event is certain to happen in a given year, it is as likely to occur in any one put of tha: year as in any other part. 
Let the contingency $c_{1}$ now represent death, and $c_{2}$ withdrawal; let the age of the individual be $x$, and let $p_{x}$ and $p_{x}^{\prime}$ denote the respective probabilities of surviving, and of non-withdrawal, for one year-the former determined upon the supposition that there are no withdrawals, and the latter npon the supposition that there are no deaths. We shall then have, by substitution in the last table, for the probability that the individual

(1) remains to the end of the year (i.e., that he neither dies nor withdraws) $\quad \cdot \quad \cdot p_{x} \cdot p_{x}^{\prime}$;

(2) disappears by death within the year $\quad \cdot \quad \cdot \frac{1}{2}\left(1-p_{x}\right)\left(1+p_{x}^{\prime}\right)$;

(3) disappears by withdrawal within the year $\cdot \frac{1}{2}\left(1-p_{x}^{\prime}\right)\left(1+p_{x}\right)$.

These expressions afford a very easy mode of constrncting a table of $\left(\lambda_{x}\right)$, the numbers remaining at the expiration of each successive year of age, as well as of the deaths and withdrawals at every age; and it will be seen that the formulx are precisely the same as would be used for calculating the probabilities of joint existence and of survivorship between two lives of equal ages, but subject to different laws of mortality. It is also evident that with the functions in question tabulated for every age we shall be furnished with every requisite for calculating directly the values of all contingencies depending upon the probabilities of death and withdrawal, whether separately or in combination with each other.

Let us now suppose that the disposition to withdraw does not vary, and put $p_{x}^{\prime}=k^{\prime}$ a constant quantity. We then have $\frac{\lambda_{x+1}}{\lambda_{x}}=\frac{l_{x+1}}{l_{x}} \cdot k$, and generally $\frac{\lambda_{x+n}}{\lambda_{x}}=\frac{l_{x+n}}{l_{x}} k^{\prime n}$, a condition which is satisfied by making $\lambda_{x}=l_{x} k^{x}$.

I shall now apply the results we have obtained to the consideration of a question of some practical importance, viz., the determination of the rates of preminm to be charged for assurances on the lives of persons exposed to risk of death from extraneous causes - that is, from canses independent of the ordinary law of mortality. The usual (perhaps I might almost say the invariable) way of dealing with these cases is to charge a fixed extra preminm, irrespective of the age of the party or of the nature of the assurance, which extra premium is discontinned when the extra risk ceases to be incurred. Now the foregoing investigation shows that we have alrearly at our command the means of determining the proper extra prominm for every case in the ordinary $\mathrm{D}$ and $\mathrm{N}$ colnmns calculated at different rates of interest, for we have seen that the constant extra risk (represented by $k^{\prime}$ ) affects these functions preeisely in the same way as the interest of money.

I shall not attempt to determine the difference between the usual mode and the correct mode of dealing with these risks in all the various forms in which the cases may present themselves, but shall confine myself to the following specimens of two of the more usual ones, viz., single life assurances for one year and for the whole term of life. The formula for an assurance for one year on a life exposed to extra risk will be $v\left(1-\frac{\lambda_{x+1}}{\lambda_{x}}\right)$ $=v\left(1-\frac{l_{x+1}}{l_{x}} k^{\prime}\right)=v-\frac{l_{x+1}}{l_{x}} k^{\prime} v=v-\frac{l_{x+1}}{l_{x}} v^{\prime}$ (putting $k v=v^{\prime}$ ). If we denote $l_{x} v^{\prime x}$ by $\mathrm{D}_{x}^{\prime}$, this becomes $v-\frac{\mathrm{D}_{x+1}^{\prime}}{\mathrm{D}_{\bar{x}}^{\prime}}$. Again, representing 
$\left(D_{x+1}^{\prime}+D_{x+2}^{\prime}+\ldots\right) \div D_{x}^{\prime}$ by $a_{x}^{\prime}$, the formula for the annnal premium for a whole life assurance becomes $\frac{1}{1+a_{x}^{\prime}}-(1-v)$. By these formula the values in the second division of the following table have been computed, $v k^{\prime}$ or $v^{\prime}$ being taken $=1 \cdot 06^{-1}$.

Carlisle Mortality-Interest 4 per Cent. Annual Premiums for an Assurance of $\mathfrak{E} 100$, with a Loading of 30 per Cent.

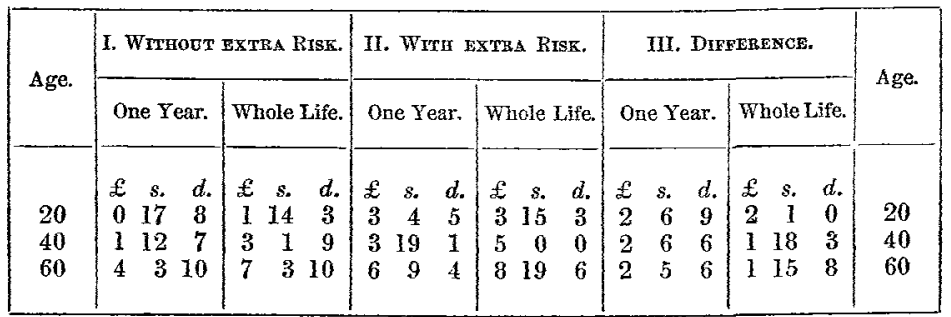

We see by this table, that when the extra risk is not infinenced by the age of the individnal, the practice of providing for it by a fixed addition to the annual premium is a very clumsy and inefficient one. In the case of "whole life" assnrances the extra preminm required is greater (and not iusignificantly so) at the lower than at the higher ages; while it is materially greater in "term" than in "whole life" assurances.

A few words now, in conclusion, in reference to the practical atility of Mr. Younger's assumed "law of withdrawal." We have seen that, in the particular case to which it has been applied, the effect of its introdnction into the calculation must be to reduce the premium; and, therefore, I think nothing more need be said against its application to problems of this class. Nor, in my opinion, would it be a whit more reasonable if applied to cases where the "valne of the policy" is less than the amount of preminm paid upon it (which is always the case where the interest on the premium paid is insufficient to cover the risk incurred), and where, consequently, the option of withdrawal would have a positive value. For in that case those policy-holders who refrain from exereising the option (which they are supposed to have paid for) are at a disadvantage as compared with those who avail themselves of it; and it would in reality be to the interest of the former to withdraw for the purpose of effecting new assurances with the premiums refunded to them. To illustrate this point, let us suppose that an ordinary life assurance is effected (by an annual premium) with the condition that, during the fret year only, the option of withdrawal shall be allowed. Let us - suppose, in the first instance, that no extra charge is made for this option; then, starting with the assumption that the value of the policy at the end of the first year is less than the preminm paid, or that

that is,

$$
1-\frac{1+a_{x+1}}{1+a_{x}}<\frac{1}{1+a_{x}}-(1-v)
$$

$$
\left(1+a_{x+1}\right)\left(\pi_{x+1}-\pi_{x}\right)<\pi_{x}
$$

( $\pi_{x}$ denoting the pure annual premium), we see from [2] that this inequation 
holds good if for pure we substitute loaded preminms, whether the loading be in the shape of a constant percentage, a constant addition, or a combination of the two. For in the first ease we should have

$$
\left(1+a_{x+1}\right)\left(c \pi_{x+1}-c \pi_{x}\right)<c \pi_{x z}
$$

which evidently follows from [2]. In the second

$$
\begin{aligned}
& \left(1+a_{x+1}\right)\left(\overline{\pi_{x+1}+c}-\overline{\pi_{x}+c}\right)<\overline{\pi_{x}+c}, \\
& \quad \text { or }\left(1+a_{x+1}\right)\left(\pi_{x+1}-\pi_{x}\right)<\overline{\pi_{x}+c,}
\end{aligned}
$$

which also follows evidently from [2]. And the third case is already proved, as it follows from (3) and (4) by precisely the same processes.

It appears, then, that whatever be the nature of the loading, $\pi_{x}^{\prime}>\left(1+a_{x+1}\right)\left(\pi_{n+1}^{\prime}-\pi_{x}^{\prime}\right)$, where $\pi_{x}^{\prime}$ denotes the loaded premium, follows from $\frac{1}{1+a_{x}}-(1-v)>1-\frac{1+a_{x+1}}{1+a_{x}}$; and, indeed, a little attention to the preceding process will show that the inequality is inereased by the loading. Now $\left(1+a_{x+1}\right)\left(\pi_{x+1}^{\prime}-\pi_{x}^{\prime}\right)$ is the equivalent which an Office wonld require to be paid for granting a new assurance at age $x+1$ at the rate of premium for age $x$; and as this has been shown to be less than $\pi_{x}^{\prime}$, it appears that when no extra charge is made for the option of withdrawal, the policyholder would derive an advantage by withdrawing and effeeting a new assurance in the way indicated. But if $\pi^{\prime}$ is greater than $\left(1+a_{x+1}\right)$ $\left(\pi_{x+1}^{\prime}-\pi_{x}^{\prime}\right)$, still more so is $\pi_{x}^{\prime}+e, e$ being any positive quantity. So that the imposition of an extra charge $(e)$, to cover the risk of withdrawal, merely has the effect of increasing the inducement to withdrawviz., the saving which the policy-holder would effect by availing himself of the option allowed him for the purpose of effecting a new assurance.

For convenience of illustration I have restricted the option of withdrawal to one year; but $I$ submit that my example is sufficient to show that the system-if a practical application of it should ever be attemptedwould rest on a very sandy foundation. As observed in my letter which appeared in July last, the option of withdrawal (being a contingency depending upon the will of the individual) is not a benefit susceptible of valuation, and it can be safely allowed only where the value of the policy is equal to or greater than the preminm paid-or, in other words, either where there has been no risk incurred, or where the interest on the premium paid is alone a sufficient compensation for the risk. In such cases no extra charge is necessary; but whether the option should not, in certain instances, be subject to a restriction as regards the health of the policyholder, is a question altogether foreign to the points I have touched upon.

$$
\text { I remain, Sir, }
$$

Your very obedient servant,

London, 24th May, 1860.

W. M. MAKEHAM.

\section{ON THE TABLES OF DEFERRED ANNUITIES AS PUBLISHED BY THE GOVERNMENT.}

\section{To the Editor.}

Drar SIR,-Since I wrote to you last year on the question of options, \&c., two letters have appeared in your Journal on the same subject; one by Mr. Makeham and the other by Mr. Younger-both writers differing 